\title{
PERENCANAAN PERBAIKAN PERKERASAN JALAN CILEUNGSI - CIBEET KABUPATEN BOGOR KM 96 STA 96+900 - STA 97+020 DENGAN METODE MANUAL DESAIN PERKERASAN JALAN
}

\author{
${ }^{1}$ Devi Setiawan, ${ }^{2}$ Yudi Sekaryadi, ${ }^{3}$ Salsa Nadia Inayah Rahmadika \\ Program Studi Teknik Sipil Fakultas Teknik Universitas Suryakancana \\ devift@unsur.ac.id, yudisekaryadi65@gmail.com ,sanaira09@gmail.com
}

\begin{abstract}
Abstrak
Kabupaten Bogor merupakan daerah yang mempunyai curah hujan tinggi, sehingga tidak luput dari bencana longsor yang dapat menyebabkan amblasnya jaringan jalan raya, Seperti yang terjadi pada ruas jalan Cileungsi - Cibeet STA 96+900 sampai dengan STA 97+020 yang mengalami kerusakan badan jalan akibat lereng yang mengalami longsor setelah beberapa hari turun hujan. perencanaan tebal perkerasan lentur mengacu pada Perencanaan Tebal Perkerasan Lentur Jalan Raya Manual Desain 2017. Dari hasil perencanaan, untuk tebal perkerasan jalan: Lapis Permukaan $=10 \mathrm{~cm}$, Lapis Pondasi Atas $=14,5 \mathrm{~cm}$, Lapis Pondasi Bawah $=30 \mathrm{~cm}$.
\end{abstract}

Kata kunci : Perkerasan Jalan, Perkerasan lentur,

\section{PENDAHULUAN}

Kabupaten Bogor memiliki luas wilayah sekitar $2.071,21 \mathrm{Km}^{2}$ terletak antara $6,19^{\circ} \mathrm{LU}-6,47^{\circ} \mathrm{LS}$ dan $106^{\circ} 1^{\prime}-107^{\circ} 103^{\prime}$ BT, yang berdekatan dengan Ibukota Negara sebagai pusat pemerintahan, dengan aktivitas pembangunan yang cukup tinggi.

Kabupaten Bogor merupakan daerah yang mempunyai curah hujan tinggi, sehingga tidak luput dari bencana longsor yang dapat menyebabkan amblasnya jaringan jalan raya, seperti yang terjadi di ruas jalan Cileungsi -Cibeet STA $96+900$ sampai dengan STA $97+020$ yang mengalami kerusakan badan jalan akibat lereng yang mengalami longsor setelah beberapa hari turun hujan.

Penulisan ini mengkaji perencanaan perbaikan perkerasan jalan pada ruas jalan tersebut. Berdasarkan latar belakang diatas, maka dapat diuraikan beberapa rumusan masalah yaitu berapakah tebal perencanaan perkerasan jalan pada perbaikan ruas Jalan Cileungsi-Cibeet KM 96 TA 96+900 - STA 97+020 Kabupaten Bogor?

\section{TINJAUAN PUSTAKA}

Perencanaan tebal perkerasan lentur Manual Desain 2017

\section{Umur Rencana}

Untuk menentukan umur rencana perkarasan dapat dilihat pada Tabel 1.
Tabel 1 Umur Rencana perkerasan jalan baru (UR)

\begin{tabular}{|c|c|c|}
\hline $\begin{array}{l}\text { Jenis } \\
\text { Perkerasan }\end{array}$ & $\begin{array}{l}\text { Elemen } \\
\text { Perkerasan }\end{array}$ & $\begin{array}{l}\text { Umur } \\
\text { Rencana } \\
\text { (Tahun) }\end{array}$ \\
\hline \multirow{5}{*}{$\begin{array}{l}\text { Perkerasan } \\
\text { Lentur }\end{array}$} & $\begin{array}{l}\text { Lapisan aspal } \\
\text { dan lapisan } \\
\text { berbutir }\end{array}$ & 20 \\
\hline & Fondasi jalan & \multirow{5}{*}{40} \\
\hline & $\begin{array}{l}\text { Semua } \\
\text { perkerasan } \\
\text { untuk daerah } \\
\text { yang tidak } \\
\text { dimungkinkan } \\
\text { pelapisan } \\
\text { ulang (overlay }\end{array}$ & \\
\hline & $\begin{array}{l}\text { jalan seperti: } \\
\text { perkotaan, } \\
\text { underpass, } \\
\text { jembatan, } \\
\text { terowongan }\end{array}$ & \\
\hline & $\begin{array}{l}\text { Cement } \\
\text { Treated Based } \\
(\mathbf{C T B})\end{array}$ & \\
\hline $\begin{array}{l}\text { Perkerasan } \\
\text { Kaku }\end{array}$ & $\begin{array}{l}\text { Lapis pondasi } \\
\text { atas, lapis } \\
\text { pondasi } \\
\text { bawah, lapis } \\
\text { beton semen, }\end{array}$ & \\
\hline
\end{tabular}




\begin{tabular}{lll}
\hline & $\begin{array}{l}\text { dan pondasi } \\
\text { jalan }\end{array}$ \\
\hline & Semua & \\
Jalan Tanpa & elemen & Minimum \\
Penutup & (termasuk & 10 \\
& pondasi jalan) & \\
\hline \multicolumn{2}{l}{ Sumber : Dinas Bina Marga MDP (2017) }
\end{tabular}

\section{Faktor pertumbuhan lalu lintas}

Pertumbuhan lalu lintas selama umur rencana dihitung dengan faktor pertumbuhan kumulatif (Cumulative Growth Factor) :

$$
\mathrm{R}=\frac{(1+0.01 i)^{V R}-1}{0.01 i}
$$

Dengan :

$\mathrm{R}$ : Faktor pengali pertubuhan lalu lintas kumulatif

$i \quad$ : Laju pertumbuhan lalu lintas tahunan (\%) UR : Umur rencana (tahun)

Tabel 2. Faktor laju pertumbuhan lalu lintas (i) $(\%)$

\begin{tabular}{lcccc}
\hline & Jawa & Sumatera & Kalimantan & $\begin{array}{l}\text { Rata-rata } \\
\text { Indonesia }\end{array}$ \\
\hline $\begin{array}{l}\text { Arteri dan } \\
\text { perkotaan }\end{array}$ & 4.80 & 4.83 & 5.14 & 4.75 \\
\hline Kolektor & 3.50 & 3.50 & 3.50 & 3.50 \\
\hline $\begin{array}{l}\text { Jalan } \\
\text { Desa }\end{array}$ & 1.00 & 1.00 & 1.00 & 1.00 \\
\hline
\end{tabular}

Sumber : Dinas Bina Marga MDP (2017)

\section{Beban sumbu standar kumulatif Cummulative Equivalent Single Axle Load (CESAL).}

Beban sumbu standar kumulatif atau Cumulative Equivalent Single Axle Load (CESAL) adalah jumlah kumulatif beban sumbu lalu lintas desain pada lajur desain selama umur rencana, yang ditentukan sebagai berikut, dengan menggunakan VDF masing-masing kendaraan niaga :

$\mathrm{CESA}_{\mathrm{TH}-1}=\left(\Sigma \mathrm{LHR}_{\mathrm{JK}} \times \mathrm{VDF}_{\mathrm{JK}}\right) \times 365 \times \mathrm{DD} \times \mathrm{DL}$ $\mathrm{x} \mathrm{R}$

Dengan :

$\mathrm{CESA}_{\mathrm{TH}-1}$ : Kumulatif lintasan sumbu standar ekivalen (equivalent standar axle) pada tahun pertama.

$\mathrm{LHR}_{\mathrm{JK}} \quad$ : Lintas harian rata - rata tiap jenis kendaraan niaga (satuan kendaraan per hari).
$\mathrm{VDF}_{\mathrm{JK}}$

DD

DL $\mathrm{R}$

: Faktor Ekivalen Beban (Vehicle

Damage Factor) tiap jenis kendaraan niaga

: Faktor distribusi arah

: Faktor distribusi lajur

:Faktor pengali pertumbuhan lalu lintas kumulatif.

\section{METODOLOGI}

Obyek penelitian untuk penulisan ini adalah Perencanaan Perkerasaan jalan di ruas jalan Cileungsi-Cibeet Kabupaten Bogor, dimulai dari STA awal 96+900 - STA 97+020, dengan panjang penanganan $120 \mathrm{~m}$.

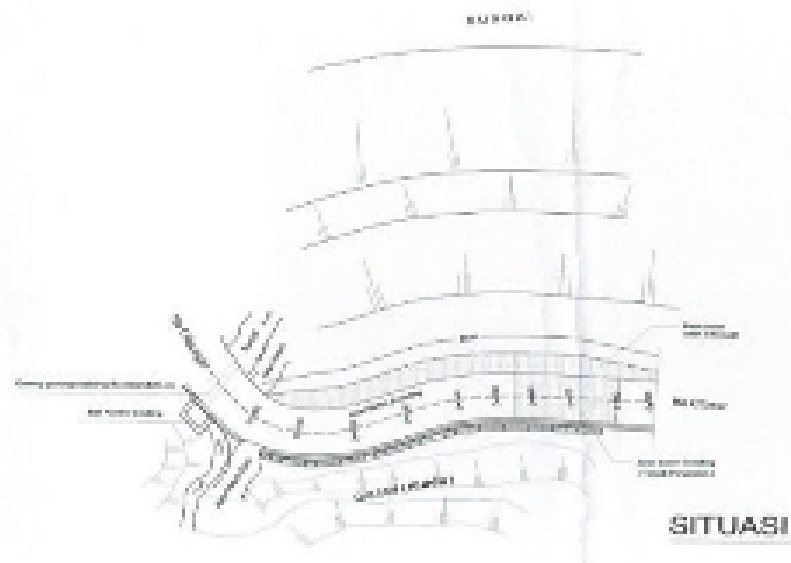

Gambar 2. Situasi Daerah Perencana Rehabilitasi Sumber: Dinas Bina Marga Provinsi Jawa Barat

(2021)

Beberapa data sekunder yang didapatkan adalah Studi literatur mempelajari kajian-kajian atau literatur yang berkaitan dengan perencanaan bangunan, di antaranya:

1. Data topografi

2. Data CBR tanah dasar

3. Data pengujian SPT

4. Data harian rata rata lalulintas

\section{PEMBAHASAN}

1. Perhitungan perencanaan perkerasan jalan dengan metode MDP 2017

Untuk menentukan tebal perkerasan lentur menggunakan metode manual desain 2017, maka terlebih dahulu dilakukan perhitungsn kumulatif beban sumbu standar (CESA). 
Tabel 3. Beban Sumbu Standar

\begin{tabular}{ccc}
\hline Gol & Jenis Kendaraan & LHR \\
\hline 1 & $\begin{array}{c}\text { Sepeda motor, skuter, } \\
\text { sepeda kumbang \& roda } 3\end{array}$ & 9624 \\
\hline 2 & $\begin{array}{c}\text { Sedan, jeep \& station } \\
\text { wagon }\end{array}$ & 623 \\
\hline 3 & $\begin{array}{c}\text { Minibus, Pick up opelet, } \\
\text { Combi }\end{array}$ & 474 \\
\hline 4 & $\begin{array}{c}\text { Micro truk \& mobil } \\
\text { hantaran }\end{array}$ & 629 \\
\hline $5 \mathrm{a}$ & Bus kecil & 65 \\
\hline $5 \mathrm{~b}$ & Bus besar & 47 \\
\hline $6 \mathrm{a}$ & Truk ringan 2 sumbu & 130 \\
\hline $6 \mathrm{~b}$ & Truk sedang 2 sumbu & 156 \\
\hline $7 \mathrm{a}$ & Truk 3 sumbu & 25 \\
\hline $7 \mathrm{~b}$ & Truk gandengan & 7 \\
\hline $7 \mathrm{c}$ & Truk semi trailer & 2 \\
\hline
\end{tabular}

Klasifikasi jalan

Umur Rencana (UR)

: Arteri - Perkotaan

Pertumbuhan lalu lintas (i)

: 20 tahun

Faktor distribusi arah (DD)

$: 4.8 \%$

$: 0.6$

Faktor distribusi lajue (DL) $\quad: 1$

\section{Menghitung CESA}

Tabel 4. Hasil Perhitungan Beban Sumbu Standar menggunakan VDF5 (ESA5)

\begin{tabular}{lllll}
\hline Jenis Kendaraan & $\begin{array}{l}\text { Konfigurasi } \\
\text { sumbu }\end{array}$ & LHR & VDF5 & ESA5 \\
\hline 1 & 2 & 3 & 4 & 5 \\
\hline $\begin{array}{l}\text { Sepeda motor, } \\
\text { skuter, sepeda } \\
\text { kumbang \& } \\
\text { roda 3 }\end{array}$ & 1.1 & 9624 & 0 & 0 \\
\hline $\begin{array}{l}\text { Sedan, jeep \& } \\
\text { station wagon }\end{array}$ & 1.1 & 623 & 0 & 0 \\
\hline $\begin{array}{l}\text { Minibus, Pick } \\
\text { up opelet, }\end{array}$ & 1.1 & 474 & 0 & 0 \\
Combi & & & & \\
\hline $\begin{array}{l}\text { Micro truk \& } \\
\text { mobil hantaran }\end{array}$ & 1.1 & 629 & 0 & 0 \\
\hline Bus kecil & 1.2 & 65 & 0.2 & 13 \\
\hline Bus besar & 1.2 & 47 & 1 & 47 \\
\hline $\begin{array}{l}\text { Truk ringan 2 } \\
\text { sumbu }\end{array}$ & 1.2 & 130 & 0.8 & 104 \\
\hline $\begin{array}{l}\text { Truk sedang 2 } \\
\text { sumbu }\end{array}$ & 1.2 & 156 & 1.7 & 265.2 \\
\hline Truk 3 sumbu & 1.22 & 25 & 64.4 & 1610 \\
\hline Truk gandengan & 1.22 & 7 & 90.4 & 632.8 \\
\hline Truk semi trailer & 1.22 & 2 & 24 & 48 \\
\hline & & ESA5 & 2720 \\
\hline & & & & \\
\hline
\end{tabular}

Nilai faktor pengali pertubuhan lalu lintas kumulatif (R) didapat dengan menggunakan rumus 2.6 yaitu :

$$
\begin{aligned}
\boldsymbol{R} & =\frac{(1+0.01 \mathrm{i})^{\mathrm{UR}}-1}{0.01 \mathrm{i}} \\
& =\frac{(1+0,01 \times 0,048)^{20}-1}{0.01 \times 0,048} \\
& =20,091
\end{aligned}
$$

Untuk mendapat nilai CESA5 digunakan rumus, yaitu :

$$
\begin{aligned}
\mathrm{CESA} 5 & =\left(\Sigma \mathrm{LHR}_{\mathrm{JK}} \times \mathrm{VDF}_{\mathrm{JK}}\right) \times 365 \times \mathrm{DD} \times \mathrm{DL} \times \mathrm{R} \\
& =2720 \times 365 \times 0,6 \times 1,0 \times 20,091 \\
& =11.968 .082,8 \mathrm{ESAL}
\end{aligned}
$$

\section{Desain tebal perkerasan lentur}

Untuk menentukan tebal perkerasan lentur yang beban sumbu kendaraanya sebesar 11.968.082,8 ESAL digunakan bagan desain 3B yang ada pada tabel 5 dengan Desain Perkerasan Lentur - Aspal dengan Lapis Pondasi Berbutir. 
Tabel 5 Desain Perkerasan Lentur - Aspal dengan Lapis Pondasi Berbutir

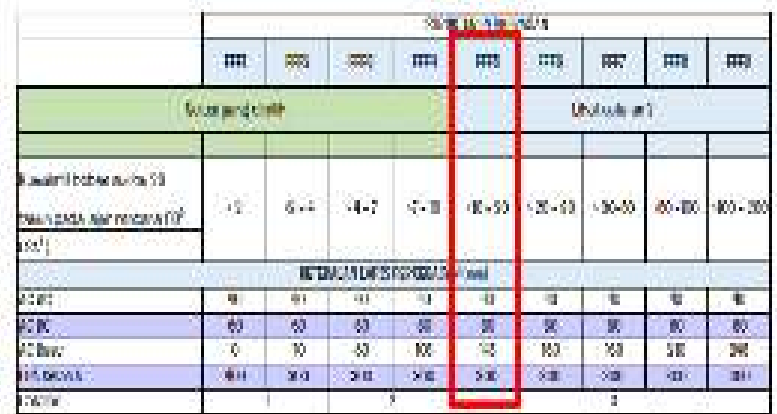

Berdasarkan bagan desain 3 diatas didapat tebal struktur perkerasan ruas jalan Cileungsi - Cibeet Km. 96+900 dengan Volume Lalu lintas yang diasumsikan sebesar 11.968.082,8 ESAL, maka struktur perkerasannnya adalah tipe FFF5. Struktur perkerasannya adalah sebagai berikut:
$\mathrm{AC}-\mathrm{WC} \quad: 4 \mathrm{~cm}$
$\mathrm{AC}-\mathrm{BC} \quad: 6 \mathrm{~cm}$
AC Base $\quad: 14.5 \mathrm{~cm}$
LPA Kelas A $\quad: 30 \mathrm{~cm}$

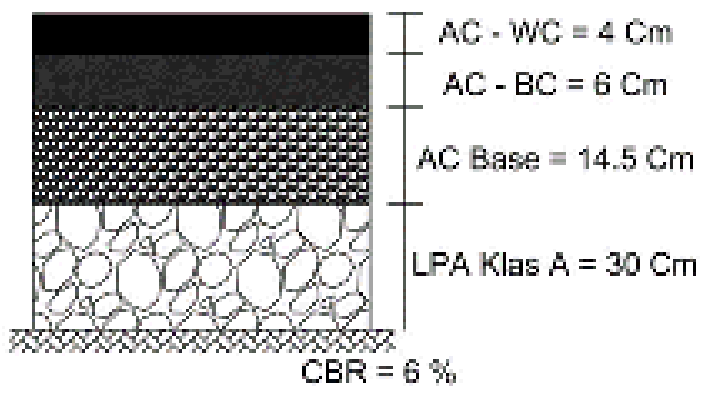

Gambar 3. Susunan lapis perkerasan rencana

\section{KESIMPULAN}

Berdasarkan hasil perhitungan perencanaan perkerasan jalan lentur menggunakan metode manual desain 2017, didapat tebal lapis perkerasan adalah sebagai berikut :
$\mathrm{AC}-\mathrm{WC} \quad: 4 \mathrm{~cm}$
$\mathrm{AC}-\mathrm{BC} \quad: 6 \mathrm{~cm}$
AC Base $\quad: 14.5 \mathrm{~cm}$
LPA Kelas A : $30 \mathrm{~cm}$

\section{DAFTAR PUSTAKA}

Bamher, Brillian Gery. Analisis Tebal Perkerasan Lentur Menggunakan Metode Manual Desain Perkerasan Jalan 2017 Pada Proyek Jalan Baru Batas Kota SingarajaMengwitani, Buleleng. Diss. Universitas Atma Jaya Yogyakarta, 2020.

Departemen Pekerjaan Umum Direktorat Jenderal Bina Marga, Manual Perkerasan Jalan (Revisi 2017) Nomor 04/SE/Db/2017.

Departemen Pekerjaan Umum Direktorat Jenderal Bina Marga, Manual Kapasitas Jalan Indonesia 1997.

Mantiri, Cynthia Claudia, Theo K. Sendow, and Mecky RE Manoppo. "Analisa Tebal Perkerasan Lentur Jalan Baru dengan Metode Bina Marga 2017 Dibandingkan Metode AASHTO 1993." Jurnal Sipil Statik 7.10 (2019).

oder EJ dan Witczak M.W. 1975, Principles of Pavement Design $2^{\text {nd }}$ Edition, A WileyInterscience Publication, New York.

Silvia, Sukirman, Perencanaan Tebal Struktur Perkerasan Lentur, Nova. Bandung: 2010 